\title{
Mental Health Carve-Outs: Effects and Implications
}

\author{
Kyle L. Grazier \\ University of Michigan \\ Laura L. Eselius \\ Harvard University
}

To control the rise in expenditures and to increase access to mental health and substance abuse (MH/SA) services, a growing number of employers and states are implementing a "carve-out." Under this arrangement, the sponsor separates insurance benefits by disease or condition, service category, or population and contracts separately for the management of care and/or associated risks. A carve-out allows a unique set of managed care techniques to be applied to a subset of particularly costly or complex benefits. This article describes various carve-out models, discusses the potential advantages and disadvantages of a full carve-out, and summarizes recent public and private sector research regarding the strategy's effects on access and use, cost savings and shifting, and quality of care. It concludes by discussing approaches to the assessment and monitoring of the processes and outcomes associated with a MH/SA carve-out.

After a decade of fast-paced growth, it appears that employers' and public sponsors' health care costs have finally begun to slow down. Efforts to manage especially costly areas, such as mental health and substance abuse (MH/SA) benefits, are contributing to the slowdown. Although the average annual growth of expenditures from 1986 to 1996 in treatment of MH/SA services has been estimated at 7 percent, individual employers and states report costs for these services outpacing those for general health services by 5

Please direct correspondence to Dr. Kyle L. Grazier. This research was supported by the National Institute of Mental Health Grant R01-MH54135. Since September 1998, Ms. Eselius has been supported by NIMH Grant T-32 MH 19733. This article, submitted to Medical Care Research and Review on July 3, 1998, was revised and accepted for publication in December 1998.

Medical Care Research and Review, Vol. 56 Supplement 2, (1999) 33-59

(C) 1999 Sage Publications, Inc. 
to 20 percent annually (Altman and Price 1993; Kimball 1994; Frank et al. 1996; The Lewin Group 1998). Similarly, Medicaid programs nationwide report high mental health services costs and are in the process of investigating alternatives to their management (Essock and Goldman 1995; The Lewin Group 1998).

In addition to addressing financial concerns, improving access to MH/SA services remains a goal. Employers and states attempt to ensure that a broad population of individuals with needs for mental health services receive the necessary services. Recent federal policies on mental health parity illustrate policy makers' attempts to emphasize the importance of access to mental health services.

Several options have been implemented in attempts to control the rise in expenditures and to increase access to mental health services. Employers have expanded techniques to manage the use of services, instituted new or enhanced employee assistance programs, or selectively contracted with what are perceived to be cost-effective providers of MH/SA services. States have mandated managed care programs for Medicaid recipients, and experiments are under way to identify sole mental health providers for special populations or to integrate $\mathrm{MH} / \mathrm{SA}$ services into current provider contracts.

One increasingly common approach to containing MH/SA costs is the mental health "carve-out" strategy, in which insurance benefits for a specific disease or condition, service category, or population are separated from other insurance benefits and managed under a different contract. In theory, costcontainment measures are likely to work differently with respect to different types of health services; thus, a carve-out allows a unique set of managed care techniques to be applied to a subset of particularly costly benefits, such as $\mathrm{MH} / \mathrm{SA}$ services. Carve-out arrangements for these services are occurring at various levels of the health care system; payers (both public and private), health plans (both indemnity and managed care), and even group practices are contracting with specialty organizations to manage a segment of their insurance risk (Frank and McGuire 1998). This, in turn, has led to increases in the numbers of specialty MH/SA managed care organizations (often referred to as behavioral health firms), the numbers of providers and enrollees participating in carve-out plans, and the types of mental health services being delivered under carve-out arrangements.

This article addresses the need for a current analysis of the literature on carve-out arrangements for MH/SA services. First, the type of carve-out strategy under consideration here and the settings in which it is found are described, along with the potential advantages and disadvantages of a $\mathrm{MH} / \mathrm{SA}$ carve-out. Next, findings from current research regarding the 
strategy's effects on access and use, cost savings and shifting, and quality of care are summarized. The article concludes with a discussion of the measurement issues and policy implications deduced from the review.

\section{THE CARVE-OUT STRATEGY}

The contractual relationships that form the bases for carve-out arrangements allow for variation in the types of services and individuals covered, as well as the extent and type of administrative functions provided by the vendor. A carve-out contract can include only mental health services, only substance abuse, or both types of services. Some include drug treatment and day treatment; most include both inpatient and outpatient service coverage. Carve-outs also can be specific to certain groups of enrollees, such as children, adolescents, or retirees; most commonly, carve-outs cover all active employees or beneficiaries and their dependents. Carve-outs may also be applied to cover benefits above a specified threshold.

An outside vendor usually handles the administration of a carve-out; this includes establishing the network of providers, negotiating fees for services, establishing protocols for treatment, and managing use. A vendor may also provide case management, operate employee assistance programs, and work with the sponsor to design the financial incentives for using network providers (Grazier et al. 1993; Frank, McGuire, and Newhouse 1995). In some cases, although less frequently, vendors employ their own clinicians and provide and manage the MH/SA services directly (Frank, McGuire, and Newhouse 1995; Feldman 1998). Most contracts are on an administrative services only (ASO) arrangement, meaning that the vendor's services are paid for in advance on a monthly fee per enrollee basis, and the vendor assumes no risk. With growing frequency, however, carve-out firms are accepting some portion of the risk for the levels of use and costs of mental health services in exchange for the monthly payment per enrollee.

Many sponsors are opting to contract directly with the growing number of specialty MH/SA managed care organizations that have sprung up within the last decade (Frank, McGuire, and Newhouse 1995). Some state Medicaid program sponsors are choosing to contract with a single vendor to serve all beneficiaries in a state (e.g., Massachusetts and Iowa), while others (e.g., Utah) are choosing to contract with a variety of local organizations to serve various geographical areas (Christianson et al. 1995; Essock and Goldman 1995; Holohan et al. 1998).

These variations in the implementation of managed behavioral health care arrangements have led to attempts to redefine, clarify, and categorize what is 
meant by a carve-out. For instance, Stroul and colleagues (1997) present the results of efforts to track health care reform components that might affect children and adolescents with emotional problems. The responses from states led the authors to characterize carve-out arrangements to reflect the extent of separation in the administration and financing of mental health services from physical health services. Separate systems were deemed full carve-outs. Some integration between mental and physical health services was titled a divided benefit. No separation was considered an integrated services system and not a carve-out arrangement.

Somewhat similar to this taxonomy is the one used by The Lewin Group (1998) as part of the SAMHSA Managed Care Tracking System. The authors also distinguish managed behavioral health care programs based on the extent of separation from physical health programs. Integrated programs are physical health programs that include a behavioral health component. A full carve-out refers to a behavioral health program that has been separated from a physical health program, while a partial carve-out refers to a separate behavioral health plan that applies once a particular threshold of benefits has been reached. Behavioral health programs not associated with physical health programs are considered stand-alone programs.

The growth in use of the full carve-out strategy has been rapid in both the private and public sectors. By 1995, 35 percent of large employers (with 5,000 or more employees) and 3 percent of relatively small employers (with fewer than 500 employees) were contracting with specialty MH/SA vendors (Frank et al. 1996). A different 1995 estimate claimed that 80 percent of Fortune 500 companies had carved out employee assistance services, mental health care, or both (Caudron 1995). On the public side, by July 1998, all but four states were implementing managed behavioral health care programs, primarily for Medicaid beneficiaries. Thirty-six states were operating or had received approval to implement 46 Medicaid waiver programs for managed behavioral health services (The Lewin Group 1998). Of the 97 managed care programs that included MH and/or SA services, 45 were stand-alone $\mathrm{MH}$ and/or SA programs not associated with physical health programs, 5 were full carveouts from physical health programs, and 3 programs were considered partial carve-outs (The Lewin Group 1998). Open Minds (1998) recently published a graphic illustrating the percentage of the U.S. population covered by managed behavioral health care as 41.2 percent in 1993 and 57.1 percent by the end of 1996.

Although the number of employers and government sponsors who are implementing a MH/SA carve-out is growing quickly, evidence is just beginning to accumulate on the effects or effectiveness of such a strategy. 


\section{CARVE-OUT POTENTIAL}

Private sector firms and public sector programs vary in their goals for carving out MH/SA services and their level of concern over various advantages and disadvantages of the strategy (Frank, McGuire, and Newhouse 1995). Sponsors report the potential to reduce $\mathrm{MH} / \mathrm{SA}$ costs through the following: (1) elimination or reduction of adverse selection, for example, by offering only one MH/SA plan and/or specific use incentives; (2) changing the cost-sharing structure to shift from more expensive to less expensive services; (3) negotiation of discounted fees for network providers; (4) more appropriate selection and efficient management of services; (5) increased risk sharing with vendors and providers; (6) improved coordination and administration of services, especially if the vendor already has a provider network in place and has experience managing $\mathrm{MH} / \mathrm{SA}$ services; and (7) the potential of economies of scale due to increased volume of services provided (Altman and Price 1993; Frank, McGuire, and Newhouse 1995; Frank et al. 1996; Frank et al. 1997; Blumenthal and Buntin 1998; Feldman 1998; Holohan et al. 1998).

Sponsors also report goals directly related to improving the processes and outcomes of care: (1) developing a larger and more specialized network of $\mathrm{MH} / \mathrm{SA}$ providers; (2) channeling patients to providers with records of providing high-quality services; (3) increasing the volume of services provided by any one provider; (4) expanding MH/SA benefits to include coverage for a wider array and continuum of services; (5) customizing benefit packages; (6) increasing consistency or uniformity of benefits and services across subgroups of the enrolled population; (7) reducing unnecessary use of services; (8) increasing patient satisfaction; (9) conducting more targeted evaluations based on specific mental health care criteria; (10) maintaining an extensive range of data on service operations, providers, and patients; and (11) increasing access to care for covered populations (Altman and Price 1993; Starr and Findlay 1994; Caudron 1995; Gold, Sparer, and Chu 1996; Blumenthal and Buntin 1998; Feldman 1998; Holohan et al. 1998).

Carve-out strategies may also afford political advantages, such as the potential to (1) increase the numbers of people covered for MH/SA services; (2) ensure that equivalent resources are used for MH/SA services, in comparison to general health services; and (3) enable a vendor to do something the sponsor may not want to do directly because of political pressures (e.g., exclude certain providers from the network) (Frank, McGuire, and Newhouse 1995; Frank et al. 1996). Additionally, implementing a carve-out for a subspecialty such as MH/SA services can serve as a way to acclimate enrollees to managed care and prepare for implementing a comprehensive managed care plan for all health services (Altman and Price 1993; Caudron 1995). 


\section{CARVE-OUT CAUTIONS}

Potential disadvantages of the MH/SA strategy relate primarily to financial and quality concerns. Financial and administrative disadvantages may include paying high administrative costs for contracting with a specialty vendor. Also, sponsors may realize only short-term savings since vendors may have little incentive to provide preventive care and detect mental health needs early, particularly if turnover in enrollment is great or lock-in provisions are minimal (Findlay 1994). Specialty vendors may have less direct control over contracted network providers and weaker incentives to reduce costs than do prepaid managed care plans, particularly if plan penetration in specialists' practices is small (Frank, McGuire, and Newhouse 1995). The carve-out strategy also may mean that sponsors must maintain two separate internal data systems, and by having two administratively separate systems with separate budgets, sponsors may lose the flexibility to apply cost savings from one area to offset costs in another (Starr and Findlay 1994; Dickey 1997). The resulting financial effects are clearly driven by the contractual relationships between the employer and the vendor on one side and the contractual relationships between the vendor and the providers on the other. Incentives for the provision of preventive or long-term services, guaranteed cost savings over prolonged fiscal periods, and coordination of and access to data must be built into initial and maintenance contracts.

Cautions related to quality include the potential that a carve-out approach might exacerbate a fragmented, uncoordinated system of health care services instead of building a fully integrated system of services that holistically addresses the general and mental health care needs of enrollees. The fact that more individuals seek mental health treatment from primary care physicians than from specialty MH/SA professionals, and that the majority of people with mental illnesses will never seek care specifically for their mental health (Howard et al. 1996), "argues powerfully for an integrated system that sensitizes primary care doctors to mental health issues and creates a coherent system of appropriate referral care" (Findlay 1994[PLEASE PROVIDE PAGE NUMBER]). The carve-out strategy, which separates MH/SA services from general health and social services, may work against the development of an integrated system and introduce confusion for enrollees and providers if coordination mechanisms are not in place (Starr and Findlay 1994; Blumenthal and Buntin 1998). While single-specialty vendors may be very good at coordinating services within their network, they may be less successful in coordinating with providers outside the network, should other types of care be needed (Lazarus 1994). "Because care is provided to persons, not conditions [as with a carve-out], any carving out of benefits can, at least in theory, create problems 
with coordination and burden-shifting" (Gold, Sparer, and Chu 1996[PLEASE PROVIDE PAGE NUMBER]).

Concerns specific to particular populations covered by carve-outs also exist. Several authors have called attention to the risks inherent in the separation of pediatric primary care services from specialty mental health services (Thorpe 1997; Holohan et al 1998). Children may be particularly vulnerable, as may be the disabled or elderly whose care already may be fragmented due to payment methodologies (Flint 1997; Stroul et al. 1997; Lillie-Blanton and Lyons 1998).

\section{EVIDENCE OF CARVE-OUT EFFECTS}

Evidence of the effects of MH/SA carve-out strategies on access and use, cost savings and cost shifting, and quality of care is just beginning to accumulate. However, corporate reports and the few empirical studies that have been published in peer-reviewed journals provide preliminary observations. Searches of MEDLINE and UNCOVER using the terms managed care and mental health; the subsequent review of bibliographies contained in the resulting articles; the authors' personal communications with individuals from SAMHSA, the National Institute of Mental Health, universities, and research firms; and a review of current issues of peer-reviewed journals yielded more than 200 articles and reports addressing various aspects of managed mental health care. Included in this set were the 11 empirical studies selected for this article (see Table 1 AUTHOR: TABLE CALLOUT OKAY HERE?). These 11 studies were selected because each directly assesses the postimplementation effects on either public or private sector enrollees of a full carve-out, in which $\mathrm{MH} / \mathrm{SA}$ services are managed separately from physical health services. This excludes four types of mental health services arrangements from this review: (1) programs that exclude mental health services altogether; (2) stand-alone programs for $\mathrm{MH}$ and/or SA that are not (and never have been) associated with physical health plans; (3) partial carve-outs or divided benefit carveouts, in which the sponsor integrates some mental health services with the physical health system while carving out the delivery and financing of, for instance, extended care services; and (4) integrated plans, in which mental health services are included in a comprehensive physical health managed care program, such as a health maintenance organization (HMO) or group practice plan (Stroul et al. 1997; The Lewin Group 1998). Arrangements that are included, therefore, may involve a MH/SA carve-out for enrollees who choose a traditional indemnity or preferred provider organization (PPO) plan (versus a managed care plan) or a single $\mathrm{MH}$ /SA carve-out for all enrollees, regardless of the plan they choose for the rest of their health benefits. Also, this 
TABLE 1 Summary Features of Selected Carve-Out Studies

\begin{tabular}{|c|c|c|c|c|c|c|c|c|}
\hline \multicolumn{4}{|c|}{ Study } & \multicolumn{5}{|c|}{ Carve-Out } \\
\hline Author(s) & $\begin{array}{c}\text { Publication } \\
\text { Date }\end{array}$ & $\begin{array}{l}\text { Number of } \\
\text { Years Studied } \\
\text { Pre/Post } \\
\text { Carve-Out }\end{array}$ & $\begin{array}{l}\text { Study } \\
\text { Sample }\end{array}$ & Population & $\begin{array}{c}\text { Publicl } \\
\text { Private } \\
\text { Enrollment }\end{array}$ & $\begin{array}{c}\text { Characteristics } \\
\text { of Vendors }\end{array}$ & $\begin{array}{c}\text { Risk- } \\
\text { Sharing } \\
\text { Arrangement }\end{array}$ & $\begin{array}{c}\text { Carve-Out } \\
\text { Start-Up } \\
\text { Year }\end{array}$ \\
\hline Callahan et al. & 1995 & 3 years $/ 1$ year & $\begin{array}{l}\text { All disabled and non- } \\
\text { disabled adults and } \\
\text { children enrolled in } \\
\text { Medicaid in } 1992 \\
(375,000)\end{array}$ & $\begin{array}{l}\text { Medicaid } \\
\text { beneficiaries in } \\
\text { Massachusetts }\end{array}$ & Public & $\begin{array}{l}1 \text { private, } \\
\text { for-profit } \\
\text { managed } \\
\text { care } \\
\text { company }\end{array}$ & $\begin{array}{l}\text { Vendor and } \\
\text { Medicaid }\end{array}$ & $\begin{array}{l}1992 \\
\text { (FY 1993) }\end{array}$ \\
\hline Christianson et al. & 1995 & 1 year / 1 year & $\begin{array}{l}\text { Medicaid beneficiaries } \\
\text { in } 3 \text { catchment areas } \\
\text { ( } 52 \% \text { of all Medicaid } \\
\text { beneficiaries) + FFS } \\
\text { Medicaid comparison } \\
\text { Group }\end{array}$ & $\begin{array}{l}\text { Medicaid } \\
\text { beneficiaries in } \\
\text { Utah }\end{array}$ & Public & $\begin{array}{l}3 \text { community } \\
\text { mental } \\
\text { health } \\
\text { centers }\end{array}$ & $\begin{array}{l}\text { Medicaid for } \\
\text { outpatient; } \\
\text { Medicaid } \\
\text { and vendors } \\
\text { for inpatient }\end{array}$ & 1991 \\
\hline Dickey et al. & 1995 & 2 years $/ 1$ year & $\begin{array}{l}\text { All adult beneficiaries } \\
\text { who were disabled } \\
\text { and treated for } \\
\text { schizophrenia, major } \\
\text { depression, or other } \\
\text { psychoses in FY 1991, } \\
\text { 1992, } 1993\end{array}$ & $\begin{array}{l}\text { Medicaid } \\
\text { beneficiaries in } \\
\text { Massachusetts }\end{array}$ & Public & $\begin{array}{l}1 \text { private, } \\
\text { for-profit } \\
\text { managed } \\
\text { care } \\
\text { company }\end{array}$ & $\begin{array}{l}\text { Vendor and } \\
\text { Medicaid }\end{array}$ & $\begin{array}{l}1992 \\
\text { (FY 1993) }\end{array}$ \\
\hline Dickey et al. & 1996 & 2 years $/ 2$ years & $\begin{array}{l}\text { All adult beneficiaries } \\
\text { who were disabled } \\
\text { and treated for } \\
\text { schizophrenia in FY } \\
\text { 1991, 1992, 1993, and/ }\end{array}$ & $\begin{array}{l}\text { Medicaid } \\
\text { beneficiaries in } \\
\text { Massachusetts }\end{array}$ & Public & $\begin{array}{l}1 \text { private, } \\
\text { for-profit } \\
\text { managed } \\
\text { care } \\
\text { company }\end{array}$ & $\begin{array}{l}\text { Vendor and } \\
\text { Medicaid }\end{array}$ & $\begin{array}{l}1992 \\
\text { (FY 1993) }\end{array}$ \\
\hline
\end{tabular}




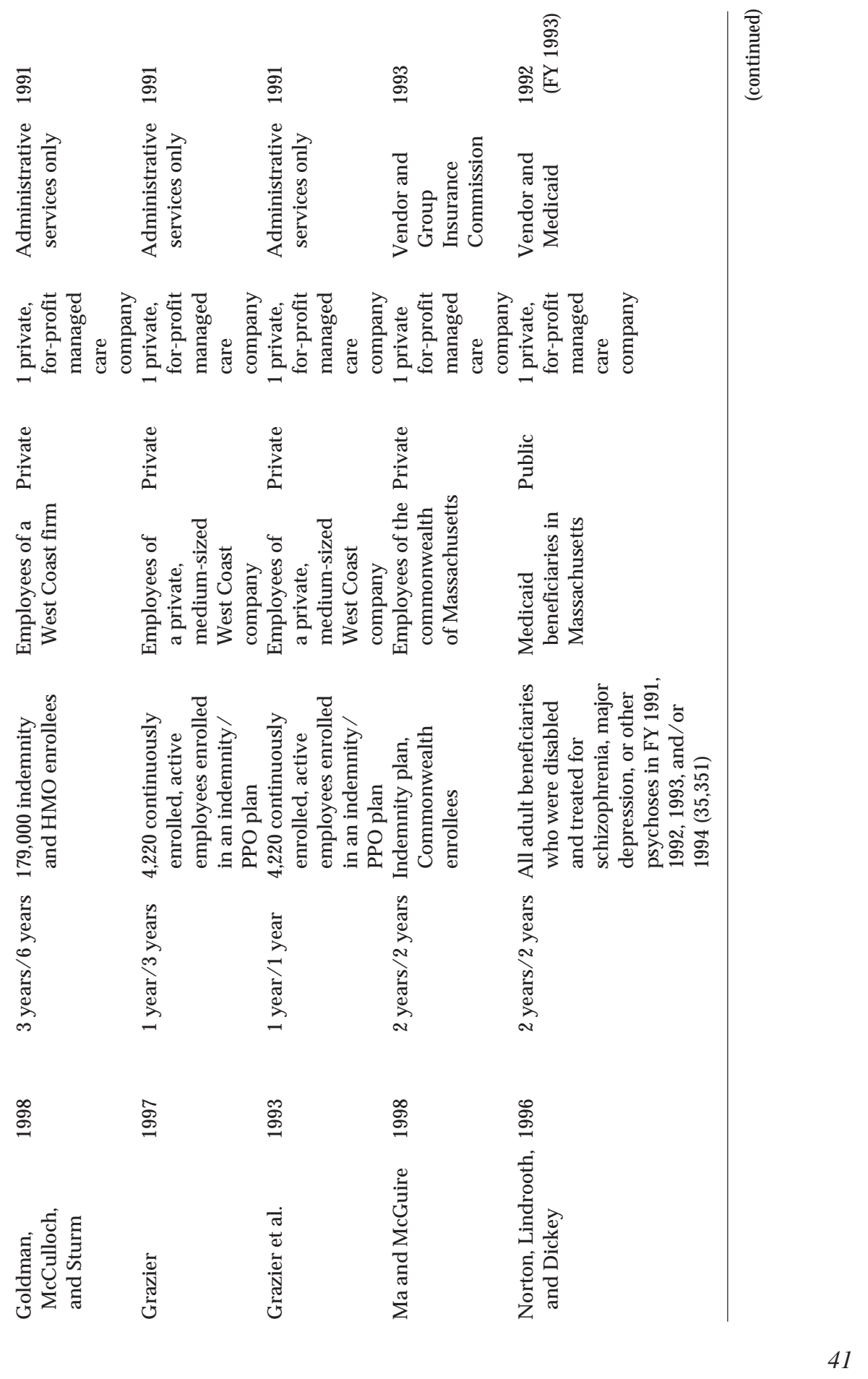


TABLE 1 Continued

\begin{tabular}{|c|c|c|c|c|c|c|c|c|}
\hline \multicolumn{4}{|c|}{ Study } & \multicolumn{5}{|c|}{ Carve-Out } \\
\hline Author(s) & $\begin{array}{c}\text { Publication } \\
\text { Date }\end{array}$ & $\begin{array}{l}\text { Number of } \\
\text { Years Studied } \\
\text { Pre/Post } \\
\text { Carve-Out }\end{array}$ & $\begin{array}{l}\text { Study } \\
\text { Sample }\end{array}$ & Population & $\begin{array}{c}\text { Public/ } \\
\text { Private } \\
\text { Enrollment }\end{array}$ & $\begin{array}{c}\text { Characteristics } \\
\text { of Vendors }\end{array}$ & $\begin{array}{c}\text { Risk- } \\
\text { Sharing } \\
\text { Arrangement }\end{array}$ & $\begin{array}{l}\text { Carve-Out } \\
\text { Start-Up } \\
\text { Year }\end{array}$ \\
\hline $\begin{array}{l}\text { Norton, Lindrooth, } \\
\text { and Dickey }\end{array}$ & 1997 & $\begin{array}{l}2 \text { years } / 2 \mathrm{nd} \\
\text { year }\end{array}$ & $\begin{array}{l}10 \% \text { random sample } \\
\text { drawn each year } \\
\text { of all Medicaid } \\
\text { beneficiaries (adults } \\
\text { and children) in } \\
\text { AFDC who had at } \\
\text { least one mental health } \\
\text { claim in FY 1991, 1992, } \\
\text { and } 1994(1993 \\
\text { unavailable) }(15,714)\end{array}$ & $\begin{array}{l}\text { Medicaid } \\
\text { beneficiaries in } \\
\text { Massachusetts }\end{array}$ & Public & $\begin{array}{l}1 \text { private, } \\
\text { for-profit } \\
\text { managed } \\
\text { care } \\
\text { company }\end{array}$ & $\begin{array}{l}\text { Vendor and } \\
\text { Medicaid }\end{array}$ & $\begin{array}{l}1992 \\
\text { (FY 1993) }\end{array}$ \\
\hline Stoner et al. & 1997 & $\begin{array}{l}3 \text { years } / 2^{1} / 2 \\
\text { years }\end{array}$ & $\begin{array}{l}\text { Medicaid beneficiaries } \\
\text { in } 3 \text { catchment areas + } \\
\text { FFS Medicaid } \\
\text { comparison group }\end{array}$ & $\begin{array}{l}\text { Medicaid } \\
\text { beneficiaries in } \\
\text { Utah }\end{array}$ & Public & $\begin{array}{l}3 \text { community } \\
\text { mental } \\
\text { health } \\
\text { centers }\end{array}$ & $\begin{array}{l}\text { 1st } 2 \text { years: } \\
\text { Medicaid for } \\
\text { outpatient; } \\
\text { Medicaid and } \\
\text { vendors for } \\
\text { inpatient; 3rd } \\
\text { year: vendors } \\
\text { at full risk for } \\
\text { outpatient and } \\
\text { inpatient }\end{array}$ & 1991 \\
\hline
\end{tabular}

Note: $\mathrm{FY}$ = fiscal year; $\mathrm{FFS}$ = fee for service; $\mathrm{HMO}=$ health maintenance organization; $\mathrm{PPO}=$ preferred provider organization; $\mathrm{AFDC}=\mathrm{Aid}$ to Families of Dependent Children. 
article focuses on the general effects of full carve-outs and excludes studies examining the effects of specific managed care techniques that are often components of carve-outs, such as use management (e.g., Stroup and Dorwart 1995; Wickizer and Lessler 1998), financial incentives in contracts (e.g., Frank and McGuire 1997), alternative organizational forms of insurance (e.g., Berndt, Frank, and McGuire 1997), and provider selection (e.g., Sturm, Meredith, and Wells 1996). Also excluded are studies examining the effects of the decision to enroll in different types of plans, such as managed care or fee for service (FFS) (e.g., Sturm et al. 1995).

\section{ACCESS AND USE}

Early research has shown that carve-outs generally result in a shift in use from inpatient services to outpatient services for MH/SA. The number or proportion of users of outpatient services and the probability of using outpatient $\mathrm{MH} / \mathrm{SA}$ services typically increase following the introduction of a carve-out strategy. The opposite seems to be true for inpatient services: the number or proportion of hospital admissions and the probability of being admitted to a hospital for MH/SA reasons tend to decline. The volume of services received-measured typically as the mean number of outpatient visits or average length of an inpatient stay-seems to decline on average.

Evidence of these trends was noted, for instance, by a large employer in California who found that 1 year following the introduction of a carve-out for outpatient MH/SA services, the probability of outpatient service use increased significantly among employees. However, the mean level of use (i.e., the mean number of visits) decreased slightly among all employees and among the subgroup of users (due to the same total number of visits occurring, but for more users) (Grazier et al. 1993). Three major factors contributed to the change among all employees: (1) as out-of-pocket price decreased, use increased; (2) as the proportion of visits to network providers relative to nonnetwork providers increased, use increased; and (3) as number of dependents increased, use decreased. The first two factors also contributed to the decrease in the mean number of visits by those who used any services. In addition, the number of years of employment was a factor: as years of employment increased, level of use decreased.

In a follow-up study of the same population, researchers found similar effects 3 years after the carve-out was implemented. In this case, however, preliminary analysis indicated that those under care at the time of the carve-out used significantly more services than those new users; their use included that from both network and nonnetwork providers. Those who had never filed a 
mental health claim prior to the carve-out were more likely to use the network providers and to report fewer than the 10-visit target use rates (Grazier 1997).

In another private sector carve-out study, Goldman, $\mathrm{McC}$ ulloch, and Sturm (1998) analyzed 6 years of data postimplementation. The authors found that access to mental health services was increasing prior to the carve-out and continued to increase after the introduction of managed care. Inpatient admissions also had started to decline prior to the carve-out, but this decline appeared to be accelerated by the carve-out. The costs per inpatient day fell dramatically as a result of the carve-out and remained steady over the next 5 years. Inpatient costs generally accounted for a smaller and smaller proportion of all payments. However, the introduction of managed care generally and changes in access to different types of alternatives to care after the carveout specifically, such as the inclusion of residential treatment and partial hospitalization, make attribution of the observed changes in cost and use difficult. That said, the types of trends noted by the authors indicate a clear effect of the introduction of managed mental health services on decreased cost and inpatient use.

Similar patterns in access, usually addressing the shorter term, have been found in reports of inpatient use in public sector programs. In the first year of a carve-out for MH/SA services in the Massachusetts Medicaid program, the proportion of beneficiaries (adults and children) receiving outpatient clinic treatment for MH/SA grew nearly 11 percent, while the volume of MH/SA services per beneficiary fell 3 percent below the expected level (Callahan et al. 1995). In contrast, the proportion of beneficiaries admitted for inpatient care declined by 7 percent and length of stay decreased by 12 percent. In total, the number of users of MH/SA services per thousand enrollees increased nearly 5 percent. The researchers also found changes in the mix of MH/SA services used. Of 13 types of mental health services, 6 showed increases and 7 showed decreases. Of 9 types of substance abuse services, 6 showed increases. Whether the change in mix of services resulted in more or less appropriate care was not addressed, although the providers who were surveyed believed no change in access had occurred following the introduction of the carve-out.

In a separate study of the same Medicaid program, Dickey and colleagues (1995) examined use patterns among the subgroup of adult beneficiaries who were psychiatrically disabled and treated for schizophrenia, major depression, or other psychoses. They found that the number of beneficiaries treated in the first year after the carve-out exceeded the prior year by 29 percent, despite a reduction in the number of available hospitals approved for treatment. This increase in the number of users of services was primarily due to the increase in outpatient use since the researchers found that the percentage of patients having at least one inpatient admission dropped by 45 percent, and 
number of admissions dropped by 46 percent. The number of multiple admissions per person also declined, as did the median number of bed-days per admission (by 2 days for general hospitals and by 9 days for state mental health hospitals). In addition, the percentage of patients using emergency rooms declined from 14 to 7 percent, and the percentage of patients receiving outpatient care following discharge declined only slightly from 51 to 49 percent. While the researchers concluded that access to care was not limited for this high-need group following implementation of the carve-out, they recommended further study to determine the effects on patient outcomes.

In a second study, Dickey and her colleagues (1996) examined use patterns among adult Medicaid beneficiaries with schizophrenia. Compared to 1 year prior to implementation of the carve-out, they found that (1) the number of treated beneficiaries grew 46 percent in the first postyear but only 3 percent in the second postyear, (2) the percentage of patients having at least one inpatient admission dropped by 52 percent in the first postyear but only by 15 percent in the second, and (3) the total number of admissions dropped by 46 percent in the first postyear but only by 16 percent in the second. The number of multiple admissions per person also declined more in the first year than in the second, as did the median number of bed days per admission. In addition, the percentage of patients using emergency rooms declined from 15 percent prior to the carve-out to 7 percent in the first year and to 12 percent in the second. The percentage of patients receiving outpatient care following discharge declined only slightly from 50 percent to 47 percent in the first postyear and 46 percent in the second postyear. Generally, changes in this subgroup's use 2 years after introduction of the carve-out mimicked those seen in the first postyear but were typically smaller in magnitude.

Additional evidence of changes in inpatient services following a carve-out has been gathered in a study of Utah's Medicaid program. While Massachusetts Medicaid contracts with a single vendor to provide MH/SA services to all beneficiaries in the state, Utah has chosen to contract with three different community mental health centers to cover a large percentage of the state's Medicaid beneficiaries (Christianson et al. 1995). This strategy has enabled researchers to compare effects between beneficiaries in the areas served by the carve-out contractors and beneficiaries who are continuing to receive services on an FFS basis in other parts of the state. In the first year, the contractors were not at financial risk for outpatient care but did share financial risk for inpatient care. Following implementation of the carve-out strategy, hospital admission rates declined by almost 17 percent in the contracting areas and remained at a lower level. The overall decline was largely attributable to a decline in admission rates at an urban site, and the decline among Aid to Families of Dependent Children (AFDC) participants was larger than the decline among non- 
AFDC participants. In contrast, outpatient and emergency room visits did not change significantly during the first year of this carve-out.

Examining post-carve-out effects in the Utah program over a longer period of time (3 $\frac{1}{2}$ years), Stoner and colleagues (1997) found that the difference between contracting (capitated) and noncontracting (noncapitated) sites in hospitalizations for treatment of mental health problems declined significantly. However, the carve-out had no significant effect on patient length of stay when hospitalized or on the number of mental health outpatient visits.

\section{COST SAVINGS AND SHIFTING}

Numerous reports from both the private and public sector suggest that a carve-out strategy for MH/SA services can reduce costs. Consider these company-reported examples:

- Before implementing a carve-out, IBM's costs for MH/SA jumped 30 percent in just 2 years, increasing from about $\$ 81$ million to $\$ 106$ million; after hiring a managed mental health care vendor, IBM's MH/SA costs dropped nearly 44 percent within 3 years (Essock and Goldman 1995).

- U.S. West reduced its MH/SA costs by 25 percent without reducing the level of benefits to employees; the company was also able to expand access to MH/SA services for employees and pave the way for introducing managed care to the union (Caudron 1995).

- After 5 years of negotiations with its vendor and implementing clinical quality measures, Union Carbide reduced per-employee MH/SA expenditures by 30 percent and improved patient satisfaction (Caudron 1995).

- After putting in a carve-out, Sterling Winthrop, a pharmaceutical company, realized a 52 percent decline in annual MH/SA costs per employee over 3 years, in spite of an increase in use of services among employees (Starr and Findlay 1994); Alcan Aluminum Corporation's MH/SA costs dropped to $\$ 70.56$ per employee in 1993 from \$169.78 in 1991 (a decline of 58 percent) (Starr and Findlay 1994); and the Orange County School Board in Orlando, Florida, cut its mental health costs in half (Caudron 1995).

- Total benefits paid per employee fell by 50 percent in 1 year after the Massachusetts Group Insurance Commission contracted with a managed behavioral health care vendor to provide a carve-out plan for state employees (Frank, McGuire, and Newhouse 1995).

Some caveats are necessary when interpreting these reports of cost savings. As Frank, McGuire, and Newhouse (1995) point out, the managed behavioral care industry, and particularly its risk-contracting portion, is very new; and research regarding its impact, as of yet, is sparse. Some of the published stud- 
ies do not adjust for the premium cost differences of the carve-out, resulting in either less or more conservative estimates of the cost savings under the contract. In addition, the observed behaviors of clients and providers faced with a new offering of a carve-out may not reflect the long-term financial consequences of the plan. Finally, changes in the coverage options for enrollees, whether under a managed care rubric or not, may confound the findings. For instance, a change in benefits to include residential treatment or day treatment concurrent with the introduction of a carve-out plan may affect the estimates of cost savings attributable to managed care (Goldman, McCullough, and Sturm 1998).

A recent study of a carve-out in an employed population indicates similar patterns in cost as those seen in use after a 4-year period. In this study, researchers used the experience of a major employer, the Commonwealth of Massachusetts, to analyze the associations among contract language, incentives, and costs. Ma and McGuire (1998) show significant cost reductions after the carve-out but caution that the design and data do not assure that the carve-out is primarily responsible for the observed decreases. Their work continues in an effort to understand the roles of several variables, such as treatment patterns, sites of care, population shifts, and price reductions.

Recent studies of public sector Medicaid programs confirm the general finding from case reports that carve-outs are associated with cost savings. In the first year of the Utah Medicaid carve-out, Christianson and colleagues (1995) found that total MH/SA expenditures per beneficiary and inpatient $\mathrm{MH} / \mathrm{SA}$ expenditures per beneficiary both declined, while outpatient and emergency room expenditures for MH/SA per beneficiary remained relatively unchanged. The reduction in inpatient expenditures was estimated to be between 44 and 47 percent (depending on the model), while the reduction in total expenditures per beneficiary was estimated to be nearly 17 percent.

In a subsequent study of the Utah Medicaid carve-out, Stoner et al. (1997) examined the effects on expenditures per beneficiary over a longer period of time ( $3 \frac{1}{2}$ years) using a model that removed time trends. In this study, the carve-out had no significant effect on overall mental health expenditures or outpatient expenditures; however, the difference in inpatient expenditures between contracting (capitated) and noncontracting (noncapitated) sites was significantly reduced.

In the first published study of the Massachusetts Medicaid program, Callahan and colleagues (1995) found that total costs for MH/SA treatment in the first year were 22 percent below projections, even after taking into account the higher administrative costs of the managed care program. Total expenditures per enrollee were 27 percent lower than expected. The vendor achieved these savings by shifting from inpatient to outpatient care when possible and by 
negotiating substantial price reductions with hospitals. Cost savings were greatest among disabled beneficiaries (total expenditures per enrollee were 37 percent lower than predicted), but nondisabled beneficiaries also experienced savings (16 percent). Seventy-eight percent of the estimated savings resulted from reduced inpatient care, and 22 percent resulted from reduced outpatient care.

In a second study of the MH/SA carve-out in Massachusetts, researchers found that inpatient expenditures for psychiatrically disabled adult Medicaid beneficiaries plummeted from $\$ 51$ million to $\$ 13$ million due to fewer admissions and lower expenditures per admission (Dickey et al. 1995). Reduced lengths of stay and lower per-diem reimbursement rates contributed to these findings. The savings in general hospitals were partially offset by increased expenditures in state mental health hospitals not included in the carve-out. Inpatient expenditures at the state hospitals increased from $\$ 65$ million to $\$ 82$ million, a 26 percent increase, due to high per-diem rates, not increased numbers of admissions or lengths of stay. When expenditures for both types of hospitals were combined, inpatient expenditures dropped 18 percent, from $\$ 116$ million to $\$ 95$ million; outpatient expenditures declined from $\$ 25$ million to $\$ 22$ million; total per person (including inpatient and outpatient care but not pharmacy, medical care, dental care, or transportation) fell from $\$ 8,600$ to $\$ 5,600$; and total expenditures on MH/SA care fell from $\$ 140$ million to $\$ 118$ million, despite an almost 30 percent increase in the number of beneficiaries.

Norton, Lindrooth, and Dickey (1996) conducted a subsequent study of the same sample of psychiatrically disabled Medicaid beneficiaries to examine the potential for cost shifting. Following the introduction of a MH/SA carveout, they found that per-person public expenditures (including inpatient care at both general and state hospitals, outpatient MH/SA care provided by the vendor, outpatient medical care paid for by Medicaid, pharmaceuticals, dental care, and transportation) were lower by 21 percent in the first year but only by 12 percent in the second year. Between the pre-carve-out year and the first post-carve-out year, the shares of expenditures accounted for by general hospital inpatient care and outpatient MH/SA care each declined by about 8 percent. Shares accounted for by pharmacy and medical care increased by about 6 percent and 5 percent, respectively, and the share accounted for by state hospital inpatient care changed by less than 1 percent. Stated differently, the portion of total expenditures paid for by the MH/SA vendor decreased, the share paid for by Medicaid increased, and the share paid by state hospitals remained about the same. Similar patterns were seen in the second postcarve-out year; however, the magnitude of the changes was smaller. The authors concluded that some cost shifting may have occurred after the introduction of a managed $\mathrm{MH} / \mathrm{SA}$ care carve-out and that some of the shifting 
may have been related to quality improvement. For instance, the authors speculate that the observed increases in medical care and pharmacy may have been due to care that was needed but was not previously received.

The results of a study examining a broader sample of Medicaid beneficiaries-a sample of adults and children who were eligible for Medicaid through the AFDC program-were somewhat different (Norton, Lindrooth, and Dickey 1997). The decline in total per-person public expenditures following implementation of the carve-out was still significant but much smaller (only 3 percent), although per-person expenditures did decline by 17 percent among sample beneficiaries who had a major mental illness. Cost shifting was less evident in this study. The largest reduction in expenditure share was for general hospital inpatient services covered by the vendor, but the decline of only 2 percent was offset by an increase of almost 2 percent in outpatient MH/SA services costs. There was a small and significant increase in the share accounted for by the pharmacy costs paid by Medicaid but virtually no change in Medicaid's medical care expenditures.

In both studies by Norton, Lindrooth, and Dickey $(1996,1997)$, the biggest savings following implementation of the carve-out were realized for Medicaid beneficiaries with the highest expenditures. Within the psychiatrically disabled subgroup, expenditures on general hospital care for beneficiaries in the highest expenditure quartile dropped by 17 percent in the first year and 9 percent in the second year, compared to much smaller declines for beneficiaries in the other quartiles. Within the broader AFDC subgroup, expenditures were highest before the carve-out and declined the most after the carve-out among beneficiaries with a major mental illness or substance abuse problem. These findings suggest that managed MH/SA services achieve the greatest savings from those who are sickest and that cost reduction and cost shifting may affect the disabled population more than the broader AFDC population.

The study of a sample of Medicaid beneficiaries suffering from schizophrenia underscores the cost-shifting phenomenon among the psychiatrically disabled population (Dickey et al. 1996). While total public expenditures on $\mathrm{MH} / \mathrm{SA}$ and general health care for this group fell by less than 1 percent by the second post-carve-out year (from $\$ 143$ million to $\$ 142$ million), cost shifting was evident. Inpatient expenditures at general hospitals dropped 35 percent (from \$26 million to \$17 million), while inpatient expenditures at state hospitals increased 2 percent (from $\$ 49$ million to $\$ 50$ million). Per-person inpatient expenditures at general hospitals (covered by the vendor) declined 23 percent, while per-person inpatient expenditures at state hospitals rose 23 percent. Outpatient MH/SA expenditures (covered by the vendor) increased 13 percent in total and 11 percent per person. Medical care expenditures (covered by Medicaid) increased 3 percent in total and 3 percent per person, and pharmacy 
costs (covered by Medicaid) increased 51 percent in total and 50 percent per person. The authors concluded that, while total MH/SA costs were contained in spite of growth in the number of treated beneficiaries (through the reduction in rates, inpatient admissions, and bed days), cost shifting to state hospitals, medical services, and pharmacies did occur within this population.

\section{QUALITY OF CARE}

The various studies of the Massachusetts Medicaid MH/SA carve-out provide some of the only published evidence to date regarding the impact of carve-out strategies on quality of care. As Dickey (1997) notes, there have been almost no systematic evaluations of aggressive mental health managed care on quality of care, functional outcomes, or patient satisfaction.

In the study of all Medicaid beneficiaries, Callahan and his colleagues (1995) found that the 30-day readmission rate remained almost the same, declining slightly from 20 to 19 percent, which suggests that patients were not being readmitted more often than before managed care was implemented. Disabled beneficiaries (mostly those eligible for Medicaid through the Supplemental Security Income program) experienced a decline in readmissions from 26 to 23 percent, while nondisabled beneficiaries (mostly those eligible for Medicaid through the AFDC program) experienced an increase in readmissions from 11 to 13 percent. Readmissions among children and adolescents increased from less than 8 percent to more than 10 percent. When asked to rate quality of care on a scale from 1 (worse) to 5 (better), providers reported that clinical quality was generally favorable on several dimensions: treatment recommendations (mean 3.80), aftercare plans (mean $=3.54$ ), length-of-stay decisions (mean $=3.53$ ), appropriate settings (mean $=3.66$ ), and overall assessment (mean $=3.23$ ). However, about 25 percent of providers felt that clinical decisions were usually inappropriate and another 25 percent had mixed views. Children's inpatient providers were more critical of clinical decisions than other providers were, and providers cited treatment of children more often as a problem area. According to the researchers, it may be that for some children with complex needs, a managed care carve-out program is less effective at coordinating care among family members, schools, and other agencies because fewer resources are available to do this.

In the study of psychiatrically disabled Medicaid beneficiaries (Dickey et al. 1995), the following changes in quality were reported 1 year after the introduction of the carve-out program: (1) the percentage of people admitted to multiple different hospitals decreased from 67 to 60 percent, (2) rapid readmissions decreased from 23 to 14 percent, and (3) the proportion of patients without any follow-up contact after discharge increased from 26 to 37 percent. 
Again, the researchers recommended further study to determine how these changes-particularly the last—affect patient outcomes.

In the study of Medicaid beneficiaries with schizophrenia, Dickey and her colleagues (1996) found the following changes 2 years after implementing the $\mathrm{MH} / \mathrm{SA}$ carve-out: (1) the percentage of patients receiving no follow-up care following discharge was up to 30 percent from 27 percent in the year prior to the carve-out, (2) the percentage of patients rehospitalized remained about the same (23 percent after compared to 24 percent before), (3) the percentage of patients admitted to more than one hospital was down to 64 percent from 68 percent, and (4) the percentage of patients visiting an emergency room decreased from 15 to 12 percent. These mixed reviews also suggest that further research is needed to evaluate changes in quality of care.

\section{DISCUSSION}

Review of the literature on managed behavioral health services, and carveouts specifically, revealed considerable activity. Forty-seven states are implementing some form of managed behavioral health program, with 36 states using the waiver mechanism to accomplish all or portions of their programs. The majority of large private employers provide coverage for managed behavioral services, most through a carve-out.

Assessing the impacts of the movement requires analysis along several dimensions. This article reviews the effects on access, use, cost, and quality of services. Published empirical research on these dimensions is sparse, and within that research is considerable variation in the manner in which key variables are measured.

In the studies reviewed here, investigators measured access in terms of actual services used: the probability of admission, the probability of any $\mathrm{MH}$ use, and levels of use conditioned on inpatient or outpatient use. Broader dimensions of access that detect aspects such as preferences for treatment, travel time, or financial resources have not been captured by the available work to date.

Researchers measure the standard clinical and economic dimensions of service use. Use commonly encompasses inpatient and outpatient services; mental health, substance abuse, and medical services; emergency room visits; and ancillary services. Services are viewed primarily as encounters, and inpatient use is measured in admission rates, readmission rates, and lengths of stay in different types of facilities (acute, residential, partial treatment). Characteristics of the face-to-face encounter, measurement of an episode, or patterns of treatment within an episode are seldom seen in use studies. 
In the studies reviewed, costs for patients' use of services and for programs are measured. Costs are measured as expenditures by and for enrollees or programs; for administrative, pharmacy, and clinical services; and for mental health, substance abuse, and other health services provided on an inpatient and outpatient basis. In addition, some cost studies include efforts to detect cost shifting by examining the transfer of the burden of paying for medical encounters and / or inpatient, outpatient, and pharmacy services to and from a vendor, state, and general hospital system. Studies that examine cost shifting among additional players, including enrollees and other types of providers, and that take into account the full scope of services involved in a medical encounter are needed.

The many dimensions of quality are perhaps even more difficult to capture. The few studies that explicitly measure quality reflect, in part, the limitations in the data and not necessarily lack of a theoretical template. The studies have relied heavily on use dimensions of quality and not necessarily on patient satisfaction or improved clinical outcomes over time. They focused primarily on readmission rates, rapid readmission rates, follow-up contacts after discharge, emergency room visits, frequency of admissions, and admissions to more than one hospital. These measures were applied to the overall sample and to subgroups of the severely mentally ill, chronically ill, children and adolescents, and schizophrenics.

This overview of early research on full MH/SA carve-outs suggests that carve-out strategies may lead to improvements in access to MH/SA services, particularly outpatient services, and significant cost savings for sponsors, typically through reductions in inpatient services. Similar increases in the probability of receiving treatment were noted in both the general population and among the more severely psychiatrically disabled after the carve-outs were implemented. In both private and public programs, inpatient use decreased after the carve-out, reducing costs. However, the sources and magnitude of the cost savings and shifting, especially over time, warrant closer examination. In many of the studies conducted to date, medical and pharmacy claims are not included in cost figures. In addition, the marginal value of substituting outpatient and/or pharmacotherapy costs for inpatient care costs is undetermined.

As noted, few studies have incorporated clinical process and outcome measures, limiting our ability to say much about the impact of carve-outs on quality of care. This review has indicated that vulnerable subgroups, including children, the disabled, and the chronically ill, may be differentially affected. In addition to measuring admission and readmission rates, measuring the management and coordination of services for these complex cases is 
important, although difficult and rare. An additional dimension of clinical vulnerability, that of persistency of use, might be detected in the measurement of the relative effect of being under care at the time of a benefit change. Comparisons between prior and new users may be useful for understanding enrollee behavior and identifying and responding to especially needy populations.

The study of the effects of benefit changes in mental health services has been driven in part by federal, state, and corporate responses to increases in health care costs and interest in improving access and quality. While this review revealed similar, positive effects from full carve-out programs on access, use, and costs, the carve-outs studied varied in many important ways. Generalizations of the effects of full carve-out programs-with their unique vendor characteristics, provider network structures, financial and risk arrangements, underlying benefit packages, and enrollee characteristics-are difficult to draw, especially with so little research that is both comparative and longitudinal. Nonetheless, it is incumbent on health services researchers to evaluate and to monitor the effects of these benefit changes across programs and time, with various methodologies and from different perspectives. It is equally important to then use this research in the creation of sound models on which to base new policy in such a significant arena as MH/SA services.

\section{REFERENCES}

Altman, L., and W. Price. 1993. Alcan Aluminum: Development of A Mental Health "Carve-Out." New Directions for Mental Health Services 59 (Fall): 55-65.

Berndt, E. R., R. G. Frank, and T. G. McGuire. 1997. Alternative Insurance Arrangements and the Treatment of Depression: What are the Facts? American Journal of Managed Care 3 (2): 243-50.

Blumenthal, D., and M. B. Buntin. 1998. Carve Outs: Definition, Experience, and Choice among Candidate Conditions. The American Journal of Managed Care 4 (June 25): SP45-57.

Callahan, J. J., D. S. Shepard, R. H. Beinecke, M. J. Larson, and D. Cavanaugh. 1995. Mental Health/Substance Abuse Treatment in Managed Care: The Massachusetts Medicaid Experience. Health Affairs 14 (3): 173-84.

Caudron, S. 1995. Carving Out Health-Care Savings. Personnel Journal (April):38-48.

Christianson, J. B., W. Manning, N. Lurie, T. J. Stoner, D. Z. Gray, M. Popkin, and S. Marriott. 1995. Utah's Prepaid Mental Health Plan: The First Year. Health Affairs 14 (3): 160-72.

Dickey, B. 1997. Assessing Cost and Utilization in Managed Mental Health Care in the United States. Health Policy 41 (Supp.): S163-74.

Dickey, B., S. T. Normand, E. C. Norton, H. Azeni, W. Fisher, and F. Altaffer. 1996. Managing the Care of Schizophrenia: Lessons from a 4-Year Massachusetts Medicaid Study. Archives of General Psychiatry 53 (October): 945-52. 
54 MCRER 56 (Supplement 2: Building Bridges IV, 1999)

Dickey, B., E. C. Norton, S. Normand, H. Azeni, W. Fisher, and F. Altaffer. 1995. Massachusetts Medicaid Managed Care Health Care Reform: Treatment for the Psychiatrically Disabled. Advances in Health Economics and Health Research 15:99-116.

Essock, S. M., and H. H. Goldman. 1995. States' Embrace of Managed Mental Health Care. Health Affairs 14 (3): 34-44.

Feldman, S. 1998. Behavioral Health Services: Carved Out and Managed. The American Journal of Managed Care 4 (June 25): SP59-67.

Findlay, S. 1994. Is a Mental Health Carve-Out More Effective? Business and Health 12 (11): 26.

Flint, S. S. 1997. Insuring Children: The Next Steps. Health Affairs 16 (4): 79-81.

Frank, R. G., H. A. Huskamp, T. G. McGuire, and J. P. Newhouse. 1996. Some Economics of Mental Health "Carve-Outs." Archives of General Psychiatry 53 (October): 933-37.

Frank, R. G., and T. G. McGuire. 1997. Savings from a Medicaid Carve-Out for Mental Health and Substance Abuse Services in Massachusetts. Psychiatric Services 48 (9): 1147-52.

- 1998. The Economic Functions of Carve Outs in Managed Care. The American Journal of Managed Care 4 (June 25): SP59-67.

Frank, R. G., T. G. McGuire, J. P. Bae, and A. Rupp. 1997. Solutions for Adverse Selection in Behavioral Health Care. Health Care Financing Review 18 (3): 109-22.

Frank, R. G., T. G. McGuire, and J. P. Newhouse. 1995. Risk Contracts in Managed Mental Health Care. Health Affairs 14 (3): 50-64.

Gold, M., M. Sparer, and K. Chu. 1996. Medicaid Managed Care: Lessons from Five States. Health Affairs 15 (3): 153-66.

Goldman, W., J. McCulloch, and R. Sturm. 1998. Costs and Use of Mental Health Services before and after Managed Care. Health Affairs 17 (3): 40-52.

Grazier, K. L. 1997. Mental Health Managed Care: Corporate Responses. Paper presented at the annual meeting of the Association for Public Policy and Management, Washington, D.C., November.

Grazier, K. L., R. M. Scheffler, S. Bender-Kitz, and P. Chase. 1993. The Effect of Managed Mental Health Care on Use of Outpatient Mental Health Services in an Employed Population. Advances in Health Economics and Health Services Research 14:71-86.

Holohan, John, S. Zuckerman, A. Evans, and S. Rangarajan. 1998. Medicaid Managed Care in Thirteen States. Health Affairs 17 (3): 43-63.

Howard, K. I., T. A. Cornille, J. S. Lyons, J. T. Vessey, R. J. Lueger, and S. M. Saunders. 1996. Patterns of Mental Health Service Utilization. Archives of General Psychiatry 53 (August): 696-703.

Kimball, M. C. 1994. The Trend to “Give What's Appropriate.” HR Magazine 39 (1): 49-52.

Lazarus, A. 1994. Disputes over Payment for Hospitalization under Mental Health "Carve-Out" Programs. Hospital and Community Psychiatry 45 (2): 115-16.

The Lewin Group. 1998. SAMHSA Managed Care Tracking System Report. Fairfax, VA: The Lewin Group.

Lillie-Blanton, M., and B. Lyons. 1998. Managed Care and Low-Income Populations: Recent State Experiences. Health Affairs 17 (3): 238-47. 
Ma, C. A., and T. G. McGuire. 1998. Costs and Incentives in a Behavioral Health CarveOut. Health Affairs 17 (2): 53-69.

Norton, E. C., R. C. Lindrooth, and B. Dickey. 1996. Cost-Shifting in Managed Care. Working paper.

. 1997. Cost-Shifting in a Mental Health Carve-Out for the AFDC Population. Health Care Financing Review 18 (3): 95-108.

Open Minds. 1998. Web site: http:/ / www.openminds.com.

Starr, B., and S. Findlay. 1994. Mental Health: Solving the Quality Problem. Business and Health 12 (11): 23-28.

Stoner, T., W. Manning, J. Christianson, D. Z. Gray, and S. Marriott. 1997. Expenditures for Mental Health Services in the Utah Prepaid Mental Health Plan. Health Care Financing Review 18 (3): 73-93.

Stroul, B. A., S. A. Pires, L. Roebuck, R. M. Friedman, B. Barrett, K. L. Chambers, and M. A. Kershaw. 1997. State Health Care Reforms: How They Affect Children and Adolescents with Emotional Disorders and Their Families. Journal of Mental Health Administration 24 (4): 386-99.

Stroup, T. S., and R. A. Dorwart. 1995. Impact of a Managed Mental Health Program on Medicaid Recipients with Severe Mental Illness. Psychiatric Services 46 (9): 885-89.

Sturm, R., C. A. Jackson, L. S. Meredith, W. Yip, W. G. Manning, W. H. Rogers, and K. B. Wells. 1995. Mental Health Care Utilization in Prepaid and Fee-For-Service Plans among Depressed Patients in the Medical Outcomes Study. HSR: Health Services Research 30 (2): 319-40.

Sturm, R., L. S. Meredith, and K. B. Wells. 1996. Provider Choice and Continuity for the Treatment of Depression. Medical Care 34 (7): 723-34.

Thorpe, K. E. 1997. Incremental Approaches to Covering Uninsured Children: Design and Policy Issues. Health Affairs 16 (4): 64-78.

Wickizer, T. M., and D. Lessler. 1998. Do Treatment Restrictions Imposed by Utilization Management Increase the Likelihood of Readmission for Psychiatric Patients? Medical Care 36 (6): 844-50. 